\title{
International Trends in Museum Interpretation of Technology and Labor
}

\author{
Laurence Gross \\ Museum of American Textile History-North Andover, Massachusetts
}

Museums have collected machines for nearly as long as they have been constructed, allowing only for the interval generally required to permit the objects to change from novel to old, quaint, or antique. As artifacts, they were at least stored, at most revered. If interpreted, they tended to be seen as part of a continuum of technological change, most often as progress. Broader import, including relationships to those who worked with the machines, rarely intruded.

A collected machine is generally the oldest or most revolutionary, a superlative attachable to it being the sine qua non of determining worthiness. Exhibits, if any, show how it works or why it is unusual. They make it seem important (as does the fact it is in a museum in the first place), productive, isolated, independent of most value systems, yet somehow "good."

I would argue that such practices are demeaning to the potential meaning and significance of technological artifacts, as well as condescending or insulting to the museum audience. They ignore the most important aspect of technology, its impact on the people to whom it relates, both producers and consumers. Furthermore, such an approach ignores the most basic factor in directing the creation of a given technology: its purpose.

The political significance of traditional museum practice is plain: collecting "technological" artifacts announces their importance; displaying them as the works of great inventors advances the great man theory of history. Attention to the parallel accomplishments of women extends, rather than solves, the problem; it does not redefine the debate. What is needed is a different use or interpretation of technology, a different history, not a fuller rendition of the old one.

Even the great person theory of history follows too small a group, ignores the masses of men and women directly and indirectly affected by technology, and thereby claims their stories are unimportant. Such collections and exhibits preach heroic individualism, defend the exploitation of labor which accompanies it, and mythify the degradation of labor at which it aims. They endorse without discussion technologies aimed at labor-cheapening machinery, a dehumanizing technology. For example, while robotics might be displayed, there would be no discussion of the fact that a company would not buy a robot capable of more functions than it needs, but conversely will take a human and de- 
vise ways to use as little as possible of the person's capacity, because the person is then more easily replaceable, its labor less expensive, but its life less complete, rewarding, satisfying.

To ignore the overall effects of technology as it is directed, to display instead isolated pieces in "how-to" or "aw-gee" exhibits, ignores the broader implications of the technology, its purposefulness, at the same time that it belittles the role of those involved in production, the workers who operate as part of a given technological system.

With such thoughts in mind, in the spring of 1984, I attended the biannual meeting of the International Committee for the Conservation of the Industrial Heritage (TICCIH, and fortunately dubbed "ticky" by the Europeans). The conference met in Lowell and Boston, Massachusetts and provided an opportunity to compare approaches to dealing with issues related to industrialism, including concerns such as mine about its interpretation in museums. The organization, founded in 1971, meets every other year to provide the opportunity for such intellectual exchange under its broad rubric: "Promoting international cooperation in the investigation, documentation, preservation, and interpretation of the world's industrial heritage," as well as to conduct business meetings. Occasional meetings are held on specialized topics, such as one on preservation and use of antique textile machines held in Belgium in 1981 and attended by Gary Kulik, Theodore Penn, and myself.

As is generally the case, the American meeting included bus tours to sites of historic industrial interest: north to Maine, south to Rhode Island, or locally, in the Merrimack Valley area. (Guidebooks available; see below.) General addresses on a variety of topics occurred occasionally, but the meat of the intellectual agenda was the "Working Sessions" in which a small group (8-20) offered prepared papers on selected subjects and carried on discussions based on those presentations.

The session on "Workers and Artifacts" brought together eight museumconnected people from the German Democratic Republic, Great Britain, Norway, Sweden, and the United States. The presentation displayed a remarkable mutuality of overall approach and general goals with useful differences in techniques and levels of attention to particular aspects of the subject.

Eberhard Wächtler (German Democratic Republic) compared the ease of portraying pre-industrial work in museum settings to the demands of interpreting heavy industry. He advocates focusing on "the function of man in the process of production," and notes that this focus complicates interpretation and renders unacceptable static presentations of machines simply conserved. He cited a silver mine in Saxony where it is possible to demonstrate mining work in all its facets, even permitting visitors to attempt the work. While dangers prohibit comparable treatments of metallurgical industry, another effort has brought an ancient forge in Thuringia to life. A water-powered reactivation of the fifteenth-nineteenth-century equipment there inadequately educated the unfamiliar until blacksmith-artists were added to truly indicate the amazing 
capabilities of workers and the primitive equipment together, bringing skill and intellect into view. The goal in these and all such instances is to connect, intellectually or even physically, modern production and the museum: "So the visitors can understand that the worker is not only a ... [servant] of machines-but also a man or woman who rules the first and most necessary process of history, the process of production."

Richard Hills (Great Britain) described recent museological changes in his country which first made glass cases, and then even fuller settings, insufficient for displaying artifacts. New interest in industrial artifacts and their operation called for demonstrations, which at times have become steady, revenues-producing operations. "At the same time . . the Government passed the Health and Safety at Work Act in 1974," and applied it to all work, including museums. Problems of physical protection, as well as noise, dust, fumes, extreme temperatures, even unpredictable flying objects must be solved for both workers and visitors at a historic setting. While craft demonstrations had offered few of these difficulties, historic industrial interpretation and these demands seem diametrically opposed. Eye shields, guards over gears, pulleys, or flyers (throstles) were completely anachronistic for many machines. Similarly, noise represents an important aspect of the effect of machines on those around them, just as the dangers associated with many emphasize the workers' skill. Consequently, careful compliance with the law blocks an intention of the exhibits: to portray different and changing working conditions. Solutions remain to be found.

David Crossley (Great Britain) made a related point when he noted that only through maintaining functioning industrial machinery could the skills required for such operations be preserved. He described a number of museum programs performing this task.

The Scandinavian representatives described well-thought-out approaches to the new task of interpreting the worker's role and culture. Bjorn Edvarsen (Norway) described the Industrial Workers' Museum at Rjukan. An electrical generating station officially owned by a group of four labor organizations, the town, and the National Electricity Board, the site aims to interpret two major themes: (1.) Energy, including its production and its relationship to peoples' daily lives and to the national economy; (2.) workers, including their lives at home, at the workplace, and as part of the local community. The breadth of this treatment bodes well for its impact on the town and the visitor.

Rune Svensk (Norway), an ethnologist, carried this approach a step further. He described, and advocated, studying industries "while they are still fully functioning." Ideally, "participation in and observation of the daily routines of the factory, 'best educate' regarding the complex process of understanding not only the technology, but especially the worker's role." Following the operatives reveals their sphere of influence, their sources of satisfaction, and other relationships to the work.

The highest development of the holistic principle came from the Swedes. 
Eva Fägerborg considered the selection of appropriate artifacts, using as criteria both what they can tell about work and how accessible to visitors their information would be. Personal equipment, entire rooms or sections thereof, complete work stations, and shopfloor innovations passed her test. In her approach symbolic meanings of objects and cultural analysis of situations require careful examination, as do questions of which aspects of work can or cannot be documented through material culture.

Birgitta Conradson (Sweden) pursued a parallel approach in applying such a logic to white-collar work, an area of worker history in danger of being ignored, she feels.

Both these latter approaches are part of SAMDOK, a program enlisting all Swedish museums in an effort to preserve contemporary society through material culture and associated techniques. Museums select subjects appropriate to their area, avoid duplication of effort (although working with others in their subject area) and devise plans to resist the "lopsidedness in collections" associated with historic collecting patterns. This effort marks an important departure from traditional museum practice and deserves close attention.

Finally, I described the exhibit designed and awaiting construction in the new home of the Museum of American Textile History. In an effort to bring museum exhibit practice in line with current research, here and elsewhere, we will utilize new scholarship and artifacts in ways which make people the exhibits' focus.

We have prepared an exhibit in four parts: handpowered production (a professional weaver); transitional or adjunct technology (a carding mill); a small and comparatively skilled factory operation (mid-nineteenth-century woolen mill); "modern" minimum skill technology (mid-twentieth-century woolen mill). Utilizing operating machinery and appropriate settings will give visitors an opportunity to grasp the types of work shown and to appreciate the reasons for their change. The nature of the machines and the work they require thereby become central to interpreting the role of people in industrial development. In conjunction, we will exhibit in separate areas the photographs, textiles, and other artifacts which can extend and enhance our operational settings.

The several approaches to interpreting technology in museums discussed at TICCIH have much in common. All intend to preserve certain instruments of production and each rejects the concept that static preservation of pieces of machinery represents an acceptable technique. This accomplishment alone stands as a major positive change in such practice. All of the participants described approaches which attempt to include the role of the worker as part of the interpretation of technological objects. However, levels of interpretation and analysis not only varied but, in fact, were not always clear. Considering the elements of difference between basically sympathetic attitudes offers a valuable exercise for those continuing to work with these problems. Moreover, a museum must collect, preserve, and interpret artifacts without undue damage 
to them, while arguing the importance of a given attitude toward the objects. It must both display a historic accuracy and attempt a contemporary contribution. Such a course removes museums from the orbit of unquestioning advocates of the status quo at the same time it requires them to properly understand what is worth preserving as evidence of that status quo, and what to say about it. It gives them the opportunity to emphasize the connections between technology and the humanities, to discuss the relationships between machinery, work, and the larger social and cultural context in which they exist.

From each speaker at TICCIH we can learn part of the path through these unfamiliar regions, just as they are learning. Preserving the past in action, recognizing that the worker is a part of the technology, learning of the workers' role, place in society and community, identifying the forces behind the work life, the motives behind the changes in technology and work, all before identifying the use of this material and the objects which must be collected to interpret it for the visitor-these are the new tasks for history museums, and the good news is that the task is being pursued on many fronts. 